Volume 9, No.1.5, 2020

International Journal of Advanced Trends in Computer Science and Engineering

Available Online at http://www.warse.org/IJATCSE/static/pdf/file/ijatcse2391.52020.pdf

https://doi.org/10.30534/ijatcse/2020/2391.52020

\title{
Low Noise Amplifier Design via Hybrid DE-ACO Optimization Algorithm
}

\author{
Soufiane Abi ${ }^{1}$, Bachir Benhala ${ }^{2}$ \\ ${ }^{1}$ University of Moulay Ismail, Morocco, sou.abi@edu.umi.ac.ma \\ ${ }^{2}$ University of Moulay Ismail, Morocco, b.benhala@fs-umi.ac.ma
}

\begin{abstract}
This paper presents a hybrid algorithm named (DE-ACO) which is combining two well-known nature-inspired algorithms namely Ant Colony Optimization (ACO) and Differential Evolution (DE). The main idea of this hybridization is to improve the performance of the ACO algorithm, it consists to use the $\mathrm{DE}$ algorithm to explore the promising search space in order to exploit the best solutions by the ACO algorithm to achieve the optimal solution. The performance of the proposed technique is firstly, evaluated over some test functions, and secondly, employed to optimize the parameters of Low Noise Amplifier (LNA) circuit. The simulation using Advanced Design System (ADS) are given to highlight the validity of this proposed method.
\end{abstract}

Key words: Low Noise Amplifier, Ant Colony Optimization, Differential Evolution, Hybridization.

\section{INTRODUCTION}

Low noise amplifier (LNA) is a crucial block in radio frequency (RF) transceivers. It is usually placed at the front side of $\mathrm{RF}$ receiver and it is main function it to amplify the weak signal received by the antenna while adding a little noise. The most important parameters required of an LNA are high gain, low noise, low power dissipation, high linearity and stable impedance. The design and optimization of the LNA is a complex and time-consuming task, because it includes an essential trade-off among various parameters and satisfaction of the required specifications [1].

In recent years, the researchers have attempted to solve hard problems using metaheuristic optimization techniques [2]. The advantage of these techniques that are efficient, robustness and easy to be implemented and employed. A set of metaheuristic techniques is proposed in the literature and are used by the designers to optimize the sizing of the analog components automatically, such as Particle Swarm Optimization [3,4], Genetic Algorithm [5], Differential Evolution [6,7,8], Artificial Bee Colony $[9,10]$ and Ant
Colony Optimization [11,12,13]. However, to get a high-quality solution by means of these metaheuristic algorithms, recent researchers are attempted to propose and develop hybrid algorithms [14]. The main purpose of hybridization is to construct an efficient algorithm by taking the benefit from the standard algorithms in order to overcome their drawbacks. In this context a lot of hybrid algorithms have been proposed in the literature and applying for the field of analog circuit design. Performance optimization of LNA using an adaptive DE and PSO (Particle Swarm Optimization) is shown in [15]. A hybrid method combining Genetic Algorithms with the Simulated Annealing (SA) technique for dealing with a current conveyor, an operational transconductance amplifier and a low noise amplifier, is presented in [16]. Hybrid algorithms (SA-ACO and GA-ACO) for optimal sizing of a CMOS second generation current conveyor and an operational amplifier, are given in [17].

Ant Colony Optimization (ACO) is a stochastic computational technique for dealing with combinatorial optimization problems. It is based on the indirect communication within a colony of artificial ants which share information of the best trails by using a chemical substance, called pheromone. However, ACO algorithm suffer from its high computation time when it compared with the Differential Evolution (DE) algorithm. In this paper a hybrid algorithm named DE-ACO is proposed. The hybridization consists of employing DE algorithm for a good initialization and to reduce the computing time of ACO Algorithm. A set of benchmark test function is used to assess the performances of the proposed algorithm. Additionally, it is applied for optimal sizing of Low noise amplifier operating at $2.4 \mathrm{GHz}$.

The remainder of this article is organized as follows: The ACO, DE and DE-ACO algorithms are described in Section 2. Section 3 presents the application of the proposed algorithm to test function. The results of optimization of LNA are presented in the section 4 , and conclusions are given in Section 5 . 


\section{METHODS}

This section, highlight structure of the Ant Colony Optimization (ACO), the Differential Evolution (DE) and the hybrid (DE-ACO) algorithm.

\subsection{Ant Colony Optimization}

The Ant Colony Optimization (ACO) is a swarm-based metaheuristic method, that imitates the behavior of ant colonies to seek the closest trail from their nests to food sources [18]. Originally, ACO was applied to deal graph-related problems, for instance the TSP problem [19]. To fix such problem, ants randomly select the vertex to attend. When ant $\mathrm{k}$ is located at the vertex $\mathrm{i}$, the probability of going to the vertex $\mathrm{j}$ is computed by the expression (1).

$$
P_{i j}^{k}= \begin{cases}\frac{\tau_{i j}^{\alpha} * \eta_{i j}^{\beta}}{\sum_{l \in J_{i}^{k}} \tau_{i 1}^{\alpha} * \eta_{i l}^{\beta}} & \text { if } \quad j \in J_{i}^{k} \\ 0 & \text { otherwise }\end{cases}
$$

Where, $\mathrm{J}_{\mathrm{i}}^{\mathrm{k}}$ is the set of neighbors of vertex $i$ of the $\mathrm{k}^{\text {th }}$ ant, $\tau_{\mathrm{ij}}$ is the amount of pheromone trail on edge (i,j), $\alpha$ and $\beta$ are weightings that control the pheromone trail and the visibility value. $\eta_{\mathrm{ij}}$ has an expression as indicated below:

$$
\eta_{i j}=\frac{1}{d_{i j}}
$$

Where $\mathrm{d}_{\mathrm{ij}}$ : is the distance between vertices $i$ and $j$.

The pheromone values are updated in each iteration by all $\mathrm{m}$ ants that have constructed a solution in the iteration itself. The pheromone value $\tau_{\mathrm{ij}}$, associated with the edge connecting vertices $i$ and $j$, is updated as shown in equation (3) :

$$
\tau_{\mathrm{ij}}=(1-\rho) * \tau_{\mathrm{ij}}+\sum_{\mathrm{k}=1}^{\mathrm{m}} \Delta \tau_{\mathrm{ij}}^{\mathrm{k}}
$$

Where $\rho$ is the pheromone evaporation rate, $m$ is the number of ants, and $\Delta \tau_{\mathrm{ij}}^{\mathrm{k}}$ is the amount of pheromone deposed on edge (i, j) by ant $\mathrm{k}$ :

$$
\Delta \tau_{\mathrm{ij}}^{\mathrm{k}}=\left\{\begin{aligned}
\frac{\mathrm{Q}}{\mathrm{L}^{\mathrm{k}}} & \text { if ant } \mathrm{k} \text { used edge }(\mathrm{i}, \mathrm{j}) \text { in its tour } \\
0 & \text { otherwise }
\end{aligned}\right.
$$

$\mathrm{Q}$ is a constant and $\mathrm{L}^{\mathrm{k}}$ is the length of the tour constructed by ant k. Figure 1 present the flowchart of the ACO algorithm.

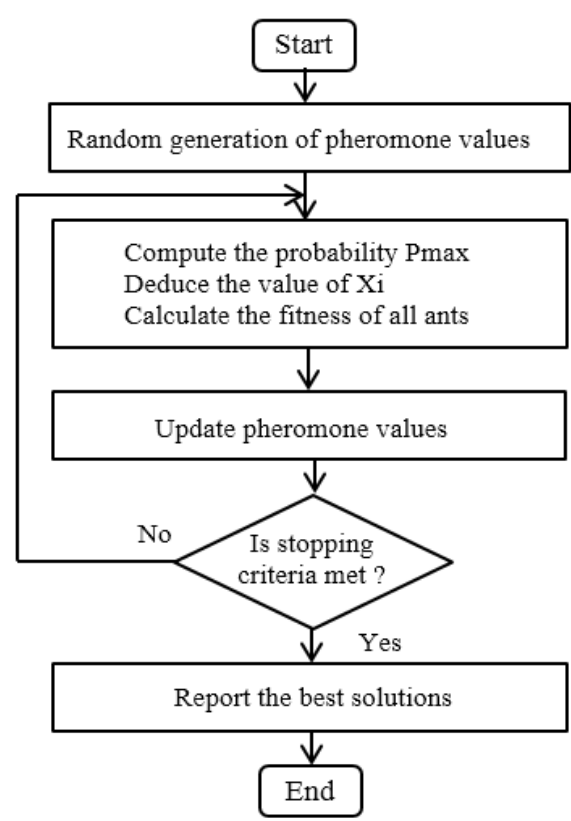

Figure 1: Flowchart of ACO algorithm

\subsection{Differential Evolution}

Differential Evolution (DE) is a stochastic population-based optimization algorithm proposed by Storn and Price in 1995 [20]. It is inspired by the evolutionary nature of the world's species. As any other evolutionary algorithm, DE algorithm seeks at evolving a population of NP, D-dimensional parameter vectors, so-called individuals. After initialization stage which consist of generation an initial population according to equation (5):

$$
X_{j i}=X_{j \min }+\operatorname{rnd}\left(X_{j \max }-X_{j \min }\right)
$$

Where, $j=1,2, \ldots, D, i=1,2, \ldots, N P$, rnd random number generate from $[0,1]$, and Xjmin, Xjmax minimum and maximum of jth population respectively.

The DE algorithm employs three operation: mutation, crossover, and selection.

The first operation is defined as follows:

$$
\mathrm{V}_{\mathrm{i}}^{\mathrm{g}+1}=\mathrm{X}_{\mathrm{r} 1}^{\mathrm{g}}+\mathrm{F}\left(\mathrm{X}_{\mathrm{r} 2}^{\mathrm{g}}-\mathrm{X}_{\mathrm{r} 3}^{\mathrm{g}}\right)
$$

$V_{i}^{g}$ is a mutant vector obtained by the differential mutation operation. Where $\mathrm{G}$ is the number of generations. $\mathrm{r} 1, \mathrm{r} 2$, and $\mathrm{r} 3(\mathrm{r} 1 \neq \mathrm{r} 2 \neq \mathrm{r} 3 \neq \mathrm{i})$ are mutually exclusive integers randomly select from the range $[1, \mathrm{NP}]$ (NP: number of population) and $F$ is a scaling factor and is in range of $[0,2]$. Once the mutation is made, the next operation is the crossover which is used to generate a trial vector $\mathrm{U}_{\mathrm{ij}}^{\mathrm{g}}$ by selecting solution component values either from $V_{\mathrm{ij}}^{\mathrm{g}}$ or the target vector $\mathrm{X}_{\mathrm{ij}}^{\mathrm{g}}$ using the following equation : 
Soufiane Abi et al., International Journal of Advanced Trends in Computer Science and Engineering, 9(1.5), 2020, 161 - 167

$$
\mathrm{U}_{\mathrm{ij}}^{\mathrm{g}}= \begin{cases}V_{\mathrm{ij}}^{\mathrm{g}} & \text { if }(\text { randj } \leq \mathrm{CR}) \text { or } \quad(\mathrm{j}=\text { jrand }) \\ X_{\mathrm{ij}}^{\mathrm{g}} & \text { otherwise }\end{cases}
$$

Where $\mathrm{j}=1,2, \ldots, \mathrm{NP}$, randj $\epsilon[0,1], \mathrm{CR}$ is the crossover rate $\epsilon[0,1]$ and jrand is a randomly selected index $\epsilon\{1,2, \ldots, N P\}$. The last operation is the selection operation which is employed in which the trial vector $\mathrm{U}_{\mathrm{i}}^{\mathrm{g}}$ replaces the target vector $X_{i}^{g}$, if the objective function value of the trial vector is better than the target vector, otherwise the target vector survives for the next generation. The selection operation is described as:

$$
X_{i}^{g+1}= \begin{cases}U_{i}^{g} & \text { if } f\left(U_{i}^{g}\right) \leq f\left(X_{i}^{g}\right) \\ X_{i}^{g} & \text { otherwise }\end{cases}
$$

where $\mathrm{f}$ is the objective function. Figure 2 present the flowchart of DE algorithm.

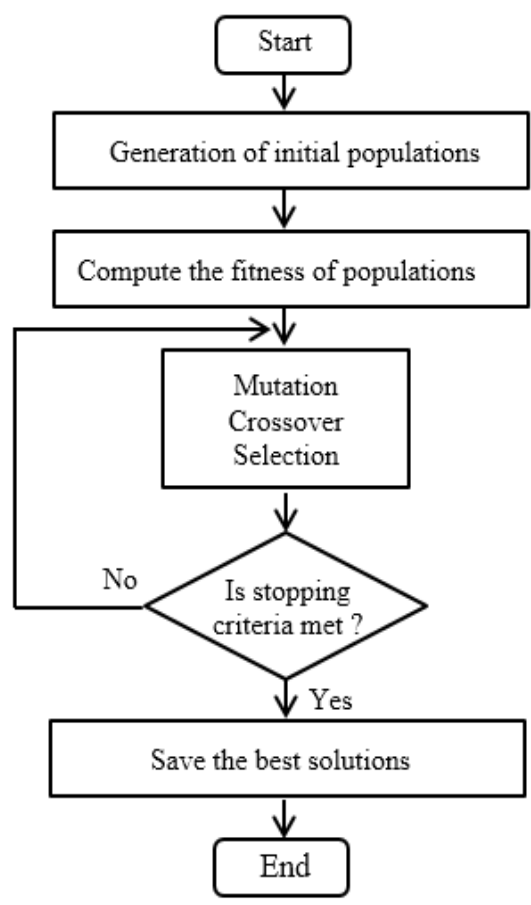

Figure 2: Flowchart of DE algorithm

\subsection{Hybrid DE-ACO Algorithm}

This section outlines the proposed algorithm which is called DE-ACO, this algorithm hybridizes the DE and ACO algorithms. The DE-ACO algorithm combines the merits of $\mathrm{DE}$ into the ACO algorithm. One of the advantages of choosing DE is that requires few control parameters and has lower time consuming, which makes it very well to hybridization. However, the ACO algorithm suffer from its main drawback which is take a higher computing time.

The main objective is to merge with the ACO algorithm, independently, the DE algorithm to get the maximum of benefit from the robustness of the two algorithms.

The structure of the hybrid DE-ACO algorithm is shown by the Figure. 3. During the initial optimization stages, the proposed algorithm starts with DE algorithm to find a near optimum solution, accelerate the convergence speed of ACO algorithm. The search process is then shifted to the ACO algorithm. Therefore, the performances of the hybrid DE-ACO algorithm are evaluated using test functions in the first case and for the optimization of low noise amplifier in the second case.

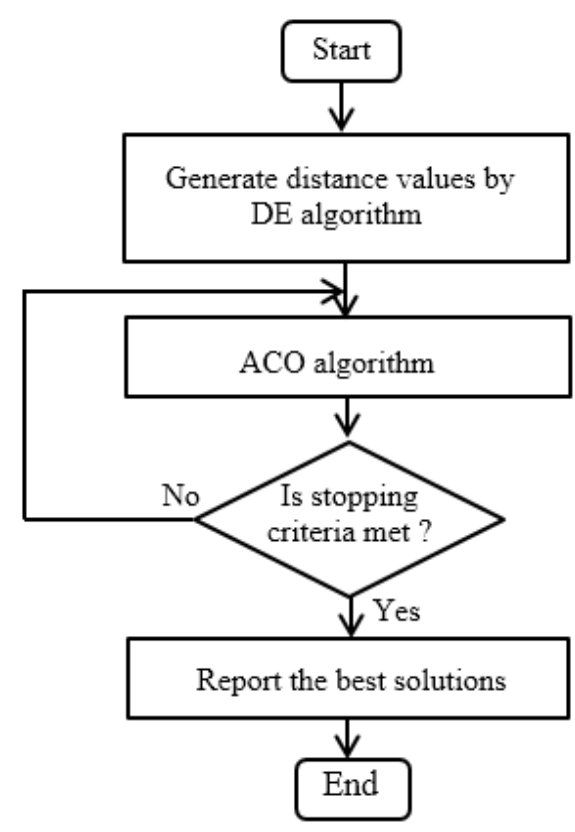

Figure 3 : Flowchart of DE-ACO algorithm

\section{APPLICATION OF DE-ACO ALGORITHM TO TEST FUNCTIONS}

In this section, the DE-ACO algorithm performances regarding the robustness and the computing time are evaluated using two test functions [21], and compared with the standard ACO algorithm. The algorithms were programmed using Matlab and a CPU i3-5005U (2.00GHz, 4.00Go) PC was employed for that purpose. The corresponding expressions of these test function are given in Table 1. 
Soufiane Abi et al., International Journal of Advanced Trends in Computer Science and Engineering, 9(1.5), 2020, 161 - 167

Table 1: Test functions

\begin{tabular}{|c|c|c|}
\hline Function & Ranges & fmin \\
\hline $\mathrm{F} 1(\mathrm{x})=\sum_{\mathrm{i}=1}^{\mathrm{n}-1}\left[100\left(\mathrm{x}_{\mathrm{i}+1}-\mathrm{x}_{\mathrm{i}}^{2}\right)^{2}+\left(\mathrm{x}_{\mathrm{i}}-1\right)^{2}\right]$ & $\begin{array}{c}{[-2.048,2.048} \\
]\end{array}$ & 0 \\
\hline $\mathrm{F} 2(\mathrm{x})=\sum_{\mathrm{i}=1}^{\mathrm{n}} \mathrm{ix}_{\mathrm{i}}^{4}+\operatorname{random}[0,1)$ & {$[-1.28,1.28]$} & 0 \\
\hline
\end{tabular}

Table 2 provides the algorithm parameters. The number of variables was $\mathrm{n}=2$, the number of populations was $\mathrm{NP}=50$, and the maximum number of iterations was $\mathrm{G}=500$.

Table 2: Algorithms parameters

\begin{tabular}{|c|c|}
\hline Scale factor $(\mathrm{F})$ & 0.9 \\
\hline Crossover rate $(\mathrm{CR})$ & 0.5 \\
\hline Pheromone factor $(\alpha)$ & 1 \\
\hline Heuristic factor $(\beta)$ & 1 \\
\hline Evaporation rate $(\rho)$ & 0.1 \\
\hline Quantity of deposit pheromone $(\mathrm{Q})$ & 0.4 \\
\hline
\end{tabular}

Due to the aspect stochastic of the used algorithms, these latter were executed 30 times for optimizing the test functions mentioned above. Table 3 gives the optimal values obtained by the ACO and DE-ACO algorithms.

Table 3: Algorithm results

\begin{tabular}{|c|c|c|}
\hline Test functions & ACO & DE-ACO \\
\hline F1 & $4 \mathrm{e}-06$ & 0 \\
\hline F2 & $3.37 \mathrm{e}-05$ & $3.65 \mathrm{e}-05$ \\
\hline
\end{tabular}

The results from Table 3 show a good agreement with the theoretical results. These two algorithms almost reach the global minima for the two functions.

The Table 4 highlight the mean execution time for each algorithm. A boxplot representation of the achieved results for the used algorithms is presented in Figure 4 and 5.

Table 4: Mean execution time in seconds

\begin{tabular}{|c|c|c|}
\hline Test functions & F1 & F2 \\
\hline ACO & 8.60 & 5.27 \\
\hline DE-ACO & 8.50 & 5.26 \\
\hline
\end{tabular}

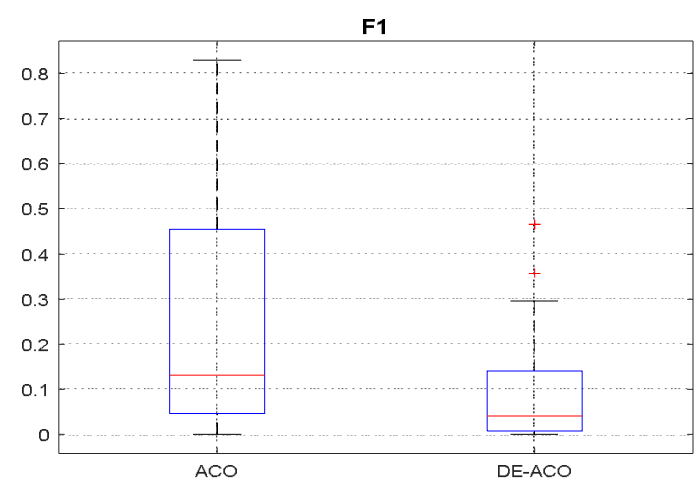

Figure 4: Boxplot of function F1

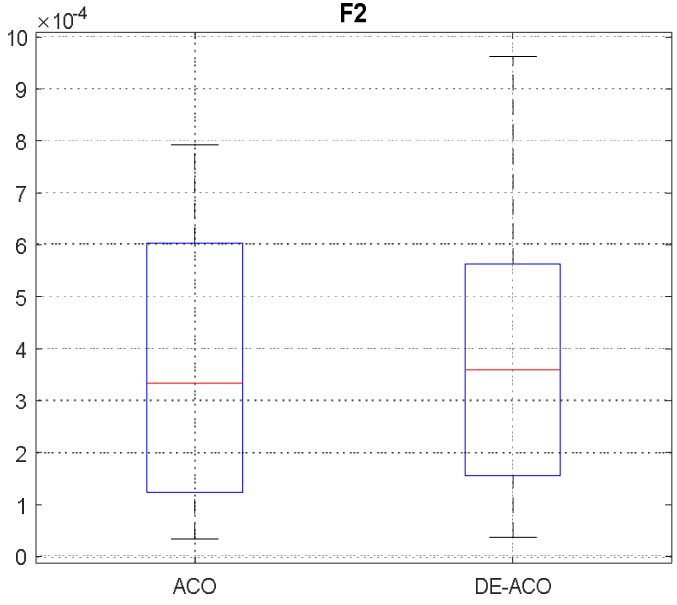

Figure 5: Boxplot of function F2

The robustness of ACO algorithm is improved by the proposed hybridization as indicated in the figures above. Regarding the computing time, the hybrid algorithm reduces the computing time for ACO algorithm.

\section{APPLICATION OF DE-ACO ALGORITHM TO THE OPTIMIZATION OF LOW NOISE AMPLIFIER}

Various topologies of LNA have been presented in the literature. The common source with degenerate inductive topology is extensively used due to it lower noise level in the amplification stage. This topology as shown in the figure 6 is adopted to our survey [22].

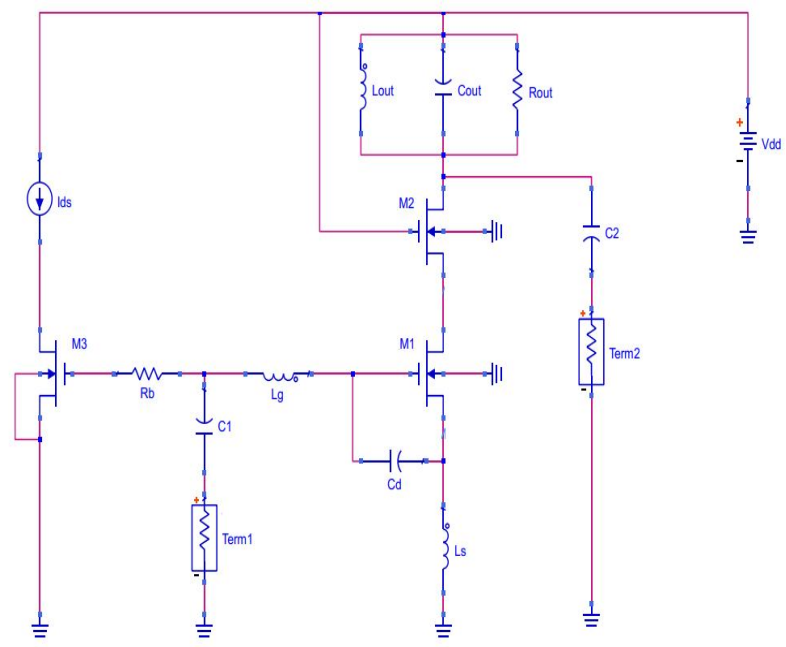

Figure 6: Schematic of LNA

The common gate transistor M2 enhances the stability of the circuit by reducing the feedback from the output to the input [23]. The input matching is achieved by means inductors (Ls) and $(\mathrm{Lg})$ and the parasitic gate to source capacitor of transistor M1. The output matching is carried out by the RLC circuit (Rout, Lout, Cout) and the equivalent output 
Soufiane Abi et al., International Journal of Advanced Trends in Computer Science and Engineering, 9(1.5), 2020, 161 - 167

impedance of transistors M1 and M2. The sub-circuit formed by transistor $\mathrm{M} 3$ and resistors $\mathrm{Rb}$ guarantees the biasing of LNA.

\subsection{Objective function}

The objective function and design constraints of LNA circuit are highlighted in this section. The main objective is the minimization of noise factor $\mathrm{F}$, which it obtained at resonance and has an expression as follows [24,22]:

$$
\mathrm{F}=1+\frac{\frac{1}{4} \gamma \mathrm{g}_{\mathrm{d} 0}+\mathrm{g}_{\mathrm{m}}^{2} \mathrm{P}^{2}\left(\mathrm{Q}^{2}+\frac{1}{4}\right) \frac{\beta}{5 \mathrm{~g}_{\mathrm{d} 0}}+\mathrm{g}_{\mathrm{m}} \mathrm{cP} \sqrt{\frac{\gamma \beta}{20}}+\frac{1}{\mathrm{R}_{\text {out }}}}{\mathrm{g}_{\mathrm{m}}^{2} \mathrm{R}_{\mathrm{s}} \mathrm{Q}^{2}}
$$

Where, $\mathrm{g}_{\mathrm{m}}$ is the transductance and $\mathrm{g}_{\mathrm{d} 0}$ the output conductance at zero bias condition. The noise parameters values for $180 \mathrm{~nm}$ are [23]: white noise factor $\gamma=1.05$, induced gate noise factor $\beta=3.8$ and correlation coefficient $c=0.2$. $\mathrm{Q}$ is the quality factor for the input circuit:

$$
\mathrm{Q}=\frac{1}{2 \omega_{0} \mathrm{R}_{\mathrm{s}} \mathrm{C}_{\mathrm{t}}}
$$

$\mathrm{P}$ is defined as:

$$
\mathrm{P}=\frac{\mathrm{C}_{\mathrm{gs}}}{\mathrm{C}_{\mathrm{t}}}
$$

Where, Cgs is the intrinsic gate capacitance of transistor M1 and $\mathrm{Ct}$ is the sum of $\mathrm{Cgs}$ and an additional capacitor $\mathrm{Cd}$. There is another practical expression of $\mathrm{F}$ as given in (12):

$$
\mathrm{NF}=10 \log _{10}(\mathrm{~F})
$$

\subsection{Constraints}

While minimizing noise figure of LNA, some important constraint must be satisfying. In order to maximize the power transfer, the impedance matching constraints can be expressed as:

$$
\begin{gathered}
\omega_{0}=\frac{1}{\sqrt{\mathrm{L}_{\mathrm{t}} \mathrm{C}_{\mathrm{t}}}} \\
\mathrm{R}_{\mathrm{s}}=\frac{\mathrm{g}_{\mathrm{m}}}{\mathrm{C}_{\mathrm{t}}} \mathrm{L}_{\mathrm{s}}=50 \text { ohms }
\end{gathered}
$$

Other constraint must verifier is:

$$
\mathrm{P} \leq 1
$$

For the capacitance Cgs is assumed to be:

$$
\mathrm{C}_{\mathrm{gs}}=\frac{2}{3} \mathrm{C}_{\mathrm{ox}} \mathrm{WL}
$$

Where, Cox is oxide capacitance.

Power dissipation for LNA expression is given in (17):

$$
P_{D}=V_{d d} I_{d s}
$$

Where, Vdd is the power supply and Ids the drain to source current through M1. The constraint for power dissipation is given as:

$$
\mathrm{P}_{\mathrm{D}} \leq \mathrm{P}_{\max }
$$

Where, Pmax is the maximum power dissipation.

For gm and gd0 their expressions are given as follows [24]:

$$
\begin{gathered}
g_{\mathrm{m}}=(0.0463) \mathrm{L}^{(-0.4489)} \mathrm{W}^{(0.5311)} \mathrm{I}_{\mathrm{ds}}^{(0.4689)} \\
\mathrm{g}_{\mathrm{d} 0}=(0.0096) \mathrm{L}^{(-0.5595)} \mathrm{W}^{(0.5194)} \mathrm{I}_{\mathrm{ds}}^{(0.4806)}
\end{gathered}
$$

The DE-ACO algorithm was applied to optimize the MOS transistors sizes W, L and Cgs, Ls and the value of the current Ids.

\section{RESULTS AND DISCUSSION}

The DE-ACO algorithm is used to minimize the noise figure (NF) of the LNA and compared to the standard ACO algorithm. The used algorithms were executed more than 30 times to obtain the best set of design parameters, using 100 populations and 1000 iterations. Table 5 provides the optimal results obtained using the $\mathrm{ACO}$ and DE-ACO algorithms for the parameters and performances of LNA.

Table 5: Optimization results for LNA when $\mathrm{Q}=4$ and Qout $=5$.

\begin{tabular}{|c|c|c|}
\hline Algorithms & ACO & $\begin{array}{c}\text { DE-AC } \\
\text { O }\end{array}$ \\
\hline $\mathrm{L}(\mu \mathrm{m})$ & 0.18 & 0.18 \\
\hline $\mathrm{W}(\mu \mathrm{m})$ & 25.10 & 25.10 \\
\hline $\mathrm{Ids}(\mathrm{mA})$ & 1 & 1 \\
\hline $\mathrm{Cgs}(\mathrm{fF})$ & 24,70 & 24.70 \\
\hline $\mathrm{Ls}(\mathrm{nH})$ & 1.20 & 1.20 \\
\hline $\mathrm{Cd}(\mathrm{pF})$ & 0.14109 & 0.14109 \\
\hline $\mathrm{Lg}(\mathrm{nH})$ & 25.326 & 25.326 \\
\hline $\mathrm{P}$ & 0.1490 & 0.1490 \\
\hline $\mathrm{gm}(\mathrm{A} / \mathrm{V})$ & 0.0069 & 0.0069 \\
\hline $\mathrm{gd} 0(\mathrm{~A} / \mathrm{V})$ & 0.0084 & 0.0084 \\
\hline $\mathrm{NF}(\mathrm{dB})$ & 0.5564 & 0.5564 \\
\hline
\end{tabular}

The values of gm, gd0, $\mathrm{Lg}$ and $\mathrm{Cd}$ are determined by the constraints. The values of the RLC output circuit are obtained by the output circuit quality factor Qout. For validation 
Soufiane Abi et al., International Journal of Advanced Trends in Computer Science and Engineering, 9(1.5), 2020, 161 - 167

reasons, the optimal design parameters are utilized to design the LNA circuit in the Advanced Design System (ADS) software using TSMC $180 \mathrm{~nm}$ CMOS technology with $1.8 \mathrm{~V}$ as the supply voltage (Vdd). Table 6 gives the comparison between optimization and simulation results. The simulation results are shown in Figure 7 and 8.

Table 6: Optimization and simulation results

\begin{tabular}{|c|c|c|c|}
\hline Algorithms & $\begin{array}{c}\text { Optimizatio } \\
\mathbf{n}\end{array}$ & Simulation & $\begin{array}{c}\text { Error(\% } \\
\text { ) }\end{array}$ \\
\hline ACO & 0.5564 & 0.556 & 0.07 \\
\hline DE-ACO & 0.5564 & 0.556 & 0.07 \\
\hline
\end{tabular}

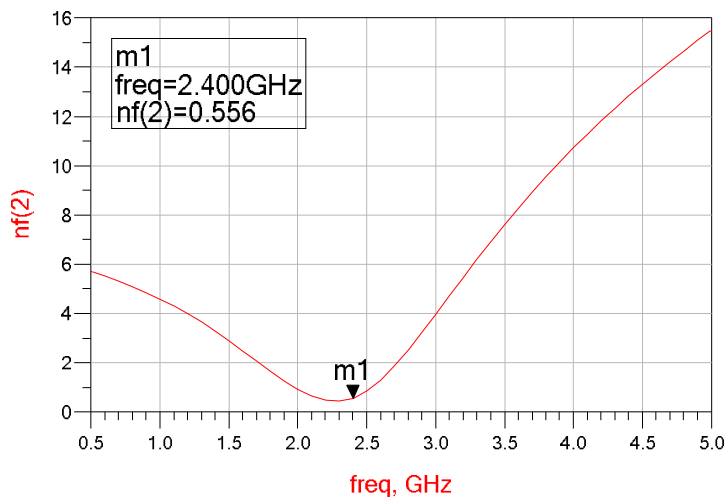

Figure 7: NF Vs. frequency for ACO

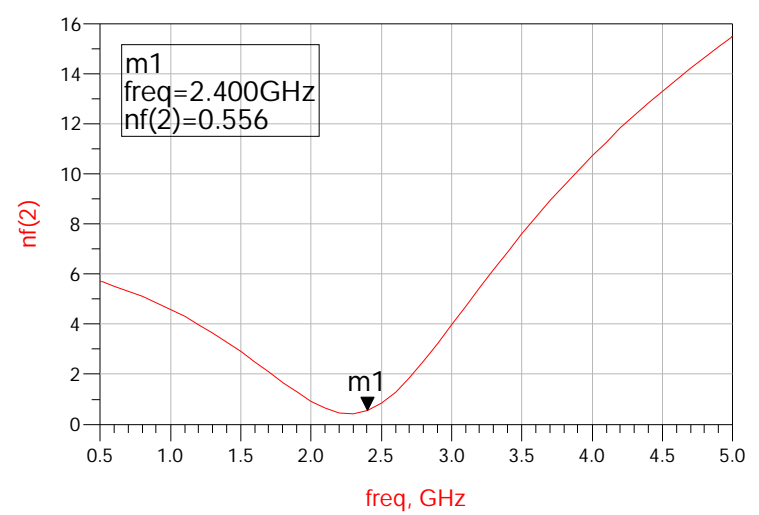

Figure 8: NF Vs. frequency for DE-ACO

The results displayed in the figures 7 and 8 and table above indicate a good agreement between optimization and simulation results.

To accomplish the comparison, the computing time and the convergence rate of the $\mathrm{ACO}$ and DE-ACO algorithms must be verified. Table 6 shows a comparison of the average time for 30 executions of each algorithm.

Table 7: Average time in seconds

\begin{tabular}{|c|c|}
\hline Algorithms & Time \\
\hline ACO & 20.93 \\
\hline DE-ACO & 19.90 \\
\hline
\end{tabular}

From this table the hybrid algorithm has small value of computing time comparing with ACO algorithm. Figure 9 show a boxplot representation of the obtained results for each algorithm.

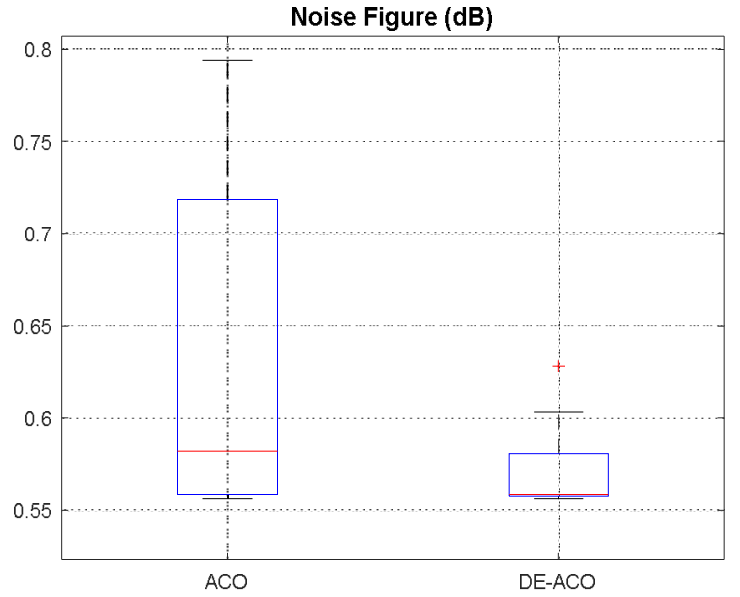

Figure 9: Boxplot of the LNA circuit of each algorithm

As indicated in the figure above, the hybrid algorithm has improved the robustness of the ACO algorithm.

Table 8 show performance comparison in term of noise figure with published works.

Table 8: Performance comparison

\begin{tabular}{|c|c|c|}
\hline Algorithm & Technology & Noise Figure (NF) \\
\hline This work & $180 \mathrm{~nm}$ & 0.5564 \\
\hline$[15]$ & $180 \mathrm{~nm}$ & 0.799 \\
\hline$[24]$ & $180 \mathrm{~nm}$ & 0.8229 \\
\hline
\end{tabular}

From the above Table, the hybrid approach provides the best performance in term of noise figure comparing with published works.

\section{CONCLUSION}

This paper treats a hybrid algorithm called DE-ACO, which is based on the Ant Colony Optimization (ACO) and Differential Evolution (DE) algorithms. This hybridization approach aims to improve the performance of the ACO algorithm for analog circuit optimization applications. Before its application for the optimal sizing of low noise amplifier circuit, the proposed DE-ACO algorithm was successfully applied to the test functions, in order to verify its viability. The results show that DE-ACO offers good optimality by reducing computation time and significantly improving robustness. The simulation results are in good agreement with the optimization results with a small error. For future work, other hybridization strategists will be proposed. 


\section{REFERENCES}

1. T. H. Lee, H. Samavati, and H. R. Rategh. 5-GHz CMOS wireless LANs, IEEE Transactions on Microwave Theory and Techniques, vol. 50, no. 1, pp. 268-280, Jan. 2002.

2. E. G. Talbi. Metaheuristics: from design to implementation, New Jersey, Wiley, 2009.

3. B. Benhala, P. Pereira, A. Sallem, (Editors), "Focus on swarm intelligence research and applications," NOVA Science Publishers, 2017.

4. M. Zemzami, A. Koulou, N. Elhami, M. Itmi, N. Hmina. Interoperability Optimization using a modified PSO algorithm. International Journal of Advanced Trends in Computer Science and Engineering. Vol.8, No. 2, pp. 101 - 107, March - April 2019.

5. B. Benhala and O. Bouattane. GA and ACO techniques for the analog circuits design optimization, Journal of Theoretical and Applied Information Technology (JATIT), Vol. 64, No 2, pp. 413-419, 2014.

6. S. Abi, B. Benhala, H. Bouyghf, M. Fakhfakh. A Comparative Study between ACO and DE Techniques by Numerical Functions Optimization, IEEE 5th International Conference on Optimization and Applications (ICOA'2019), Kenitra, Morocco, April 25-26, 2019.

7. I. El hajjami, B. Benhala, and H. Bouyghf. Optimal Design of RF Integrated Inductors via Differential Evolution Algorithm, 1st International Conference on Innovative Research in Applied Science, Engineering and Technology (IRASET), Meknes, Morocco, 2020, pp. 1-6.

8. I. Hilary. Okagbue, O. Muminu. Adamu, A. Timothy. Anake, S. Ashiribo. Wusu. Quantile Approximation of the Erlang Distribution using Differential Evolution Algorithm, International Journal of Advanced Trends in Computer Science and Engineering, Vol. 9, No. 3, pp. 2746-2755. May-June 2020.

9. S. Abi, H. Bouyghf, A. Raihani, and B. Benhala. Swarm Intelligence Optimization Techniques for an Optimal RF Integrated Spiral Inductor Design. International Conference on Electronics, Control, Optimization and Computer Science (ICECOCS), Kenitra, pp. 1-7, 2018.

10. H. Bouali, B. Benhala, and H. Bouyghf. Performance study of Multi-Objective Artificial Bee Colony (MOABC) Algorithm by Numerical Problems Benchmark, 1st International Conference on Innovative Research in Applied Science, Engineering and Technology (IRASET), Meknes, Morocco, pp. 1-6, 2020.

11. L. Kritele, B. Benhala, and I. Zorkani. Ant Colony Optimization for Optimal Analog Filter Sizing, Chapter 10, Book: Focus on swarm intelligence research and applications, Eds., B. Benhala, P. Pereira and A. Sallem, NOVA Science Publishers, pp. 193-220, 2017.

12. B. Benhala. Sizing of an inverted current conveyors by an enhanced ant colony optimization technique,
Conference on Design of Circuits and Integrated Systems (DCIS), Granada, 2016, pp. 1-5.

13. L. Kritele, B. Benhala, and I. Zorkani. Ant Colony Optimization for Optimal Low-Pass Filter Sizing, book: Bioinspired Heuristics for Optimization, Edts: Talbi, El-Ghazali, Nakib, Amir (Eds.), Studies in Computational Intelligence book series, Springer International Publishing, Volume 774, eBook ISBN 978-3-319-95104-1, Chapter 18, pp. 283-299, 2019.

14. E. G. Talbi. A Taxonomy of Hybrid Metaheuristic, Journal of Heuristics, vol. 8, no. 5, pp. 541-546, 2002.

15. S. Mallick, J.R. Akhil, A. Dasgupta, R. Kar, D. Mandal, and S.P. Ghoshal. Optimal design of $5.5 \mathrm{GHz}$ CMOS LNA using hybrid fitness based adaptive DE with PSO. In: 5th International Electrical Engineering Congress (IEECON), 2017, pp. 1-4.

16. M. Fakhfakh, A. Sallem, M. Boughariou, S. Bennour, E. Bradai, E. Gaddour and M. Loulou. Analogue Circuit Optimization through a Hybrid Approach, a chapter in Intelligent Computational Optimization in Engineering, (Eds.) M. Köppen, G. Schaefer, A. Abraham, pp.297-327, 2011.

17. B. Benhala. Hybridization Approches of Metaheuristics for Optimal Analog Circuit Design, International journal of microwave and optical technology. vol. 9, no. 6, pp. 421-428, November 2014.

18. Y. Jinhui, S. Xiaohu, M. Maurizio and L. Yanchun. An ant colony optimization method for generalized TSP problem, Progress in Natural Science, Vol. 18, pp 1417-1422, 2008.

19. M. Dorigo and T. Stützle. The ant colony optimization metaheuristic: Algorithms, applications and advances, In Handbook of Metaheuristics, Kluwer Academic Publishers, pp. 251-285, 2002.

20. K. Price, R. Storn, and A. Lampinen. Differential Evolution a Practical Approach to Global Optimization, Springer Natural Computing Series, 2005.

21. M. Jamil, X.S. Yang, H.J, Zepernick. Test functions for global optimization: a comprehensive survey, In: Swarm Intelligence and Bio-Inspired Computation, 2013 pp. 193-222.

22. P. Andreani, and H. Sjoland. Noise Optimization of an Inductively Degenerated CMOS Low Noise Amplifier, IEEE Transactions on circuits and systems, Vol. 48, pp. 835-841, 2001.

23. B. Razavi. RF Microelectronics. Prentice Hall, New Jersey, 1998.

24. H.K. Hoe. David, and J. Xiaoyu. The Design of Low Noise Amplifiers in Deep Submicron CMOS Process: A convex Optimization Approach. Hindawi Publishing Corporation VLSI Design, ID 312639, V, 2015. 